\title{
Trichoderma-Induced Acidification Is an Early Trigger for Changes in Arabidopsis Root Growth and Determines Fungal Phytostimulation
}

OPEN ACCESS

Edited by:

Jesús Mercado-Blanco,

Consejo Superior de Investigaciones

Cientificas (CSIC), Spain

Reviewed by:

Sabrina Sarrocco,

University of Pisa, Italy

David Ruano-Rosa,

Instituto de Agricultura Sostenible-

National Research Council, Spain

*Correspondence:

Alfredo Herrera-Estrella alfredo.herrera@cinvestav.mx

Specialty section: This article was submitted to

Plant Microbe Interactions,

a section of the journal

Frontiers in Plant Science

Received: 29 March 2017 Accepted: 02 May 2017

Published: 17 May 2017

Citation:

Pelagio-Flores $R$

Esparza-Reynoso S,

Garnica-Vergara A, López-Bucio J and Herrera-Estrella A (2017)

Trichoderma-Induced Acidification Is an Early Trigger for Changes

in Arabidopsis Root Growth

and Determines Fungal

Phytostimulation.

Front. Plant Sci. 8:822.

doi: 10.3389/fpls.2017.00822

\section{Ramón Pelagio-Flores'1, Saraí Esparza-Reynoso², Amira Garnica-Vergara², José López-Bucio² and Alfredo Herrera-Estrella ${ }^{1 *}$}

' Laboratorio Nacional de Genómica para la Biodiversidad-Unidad de Genómica Avanzada, Centro de Investigación y de Estudios Avanzados del IPN, Irapuato, México, ${ }^{2}$ Instituto de Investigaciones Químico-Biológicas, Universidad Michoacana de San Nicolás de Hidalgo, Morelia, México

Trichoderma spp. are common rhizosphere inhabitants widely used as biological control agents and their role as plant growth promoting fungi has been established. Although soil pH influences several fungal and plant functional traits such as growth and nutrition, little is known about its influence in rhizospheric or mutualistic interactions. The role of $\mathrm{pH}$ in the Trichoderma-Arabidopsis interaction was studied by determining primary root growth and lateral root formation, root meristem status and cell viability, quiescent center (QC) integrity, and auxin inducible gene expression. Primary root growth phenotypes in wild type seedlings and STOP1 mutants allowed identification of a putative root $\mathrm{pH}$ sensing pathway likely operating in plant-fungus recognition. Acidification by Trichoderma induced auxin redistribution within Arabidopsis columella root cap cells, causing root tip bending and growth inhibition. Root growth stoppage correlated with decreased cell division and with the loss of QC integrity and cell viability, which were reversed by buffering the medium. In addition, stop1, an Arabidopsis mutant sensitive to low $\mathrm{pH}$, was oversensitive to $T$. atroviride primary root growth repression, providing genetic evidence that a $\mathrm{pH}$ root sensing mechanism reprograms root architecture during the interaction. Our results indicate that root sensing of $\mathrm{pH}$ mediates the interaction of Trichoderma with plants.

Keywords: plant growth, root development, symbiosis, soil pH, pH sensing, biocontrol

\section{INTRODUCTION}

Plants are constantly exposed to biotic or abiotic stimuli and adjust their growth and developmental patterns to adapt and survive. Members of the fungal genus Trichoderma are frequently found in the rhizosphere, a narrow soil zone influenced by roots, where many species establish beneficial interactions with plants either antagonizing phytopathogens or directly influencing morphogenesis (Benítez et al., 2004; Harman et al., 2004; Harman, 2006; Druzhinina et al., 2011; Hermosa et al., 2012).

A complex chemical interaction is established between Trichoderma and their plant hosts comprising volatile and diffusible secondary metabolites, small peptides, and/or antibiotics, which influence root growth, branching and absorptive capacity (Samolski et al., 2012; López-Bucio et al., 2015). T. virens produces and releases auxinic compounds, including indole-3-ethanol (IET), indole-3-acetaldehyde (IALD), indole-3-carboxaldehyde (ICALD), and indole-3-acetic acid (IAA) 
(Contreras-Cornejo et al., 2009), whereas T. atroviride and T. asperellum produce the volatile 6-pentyl-2H-pyran-2-one (6-PP), which modulates plant growth and root system architecture (Kottb et al., 2015; Garnica-Vergara et al., 2016). T. atroviride also produces ethylene, and ethylene-related mutants etr1 and ein 2 show defective root-hair induction and enhanced primary-root growth inhibition when co-cultivated with this fungus (Contreras-Cornejo et al., 2015). Thus, auxin and ethylene (ET) signaling play a major role in the Arabidopsis root developmental response to Trichoderma. Furthermore, Trichoderma induces plant defense responses and improves crop performance under different stress conditions (Mastouri et al., 2010, 2012; Contreras-Cornejo et al., 2011, 2014a; Salas-Marina et al., 2011; Rawat et al., 2013; Hashem et al., 2014).

The rhizosphere is the region where plant roots, soil conditions, and microorganisms interact. While Trichoderma root colonization is often of benefit to plants, improves nutrition, and/or enhances the degradation of toxic chemicals, the mechanisms of phytostimulation remain mostly unknown. The rhizosphere physicochemical conditions are the major driving forces influencing microbe proliferation (Husson, 2013), and no other single chemical soil characteristic is more important in determining the success of plants and soil microbes than $\mathrm{pH}$ (Brady and Weil, 1999). Optimum $\mathrm{pH}$ for growth varies considerably among plants, but most cultivated species grow well on slightly acid or neutral soils, in which root cells function properly (Marschner, 1991; Brady and Weil, 2010; Shavrukov and Hirai, 2016). However, when soil pH becomes more acid (lower than 5.5), root growth is repressed and plant yield decreases, correlating with an increase in toxic levels of aluminum $\left(\mathrm{Al}^{3+}\right)$, manganese $\left(\mathrm{Mn}^{2+}\right)$, iron $\left(\mathrm{Fe}^{2+}\right)$, and protons $\left(\mathrm{H}^{+}\right)$, as well as decrease in the availability of phosphorous (P), calcium $\left(\mathrm{Ca}^{2+}\right)$, and magnesium $\left(\mathrm{Mg}^{2+}\right.$ ) (von Uexküll and Mutert, 1995; Kochian et al., 2004; Fan et al., 2016a; Shavrukov and Hirai, 2016). An acidic $\mathrm{pH}$ further inhibits root cell division and elongation, and compromises meristem cell viability (Koyama et al., 1995; Yokota and Ojima, 1995; Lager et al., 2010; Graças et al., 2016).

In fungi, $\mathrm{pH}$ is also an important factor that affects growth, development and competition (Alkan et al., 2013). Several pathogenic fungi acidify the $\mathrm{pH}$ of the growth media such as Penicillium sp., Botrytis cinerea, Sclerotinia sclerotiorum, Aspergillus niger, and Phomopsis mangiferae; whereas Colletotrichum sp, Alternaria alternata, and Fusarium oxysporum alkalinize it, and this property is strongly involved in virulence regulation (Alkan et al., 2013; Prusky et al., 2016). Trichoderma spp. grows better in acidic conditions with an optimal growth at $\mathrm{pH}$ ranging from 4 to 6 , and they can modify the $\mathrm{pH}$ of the rhizosphere (Trushina et al., 2013; Singh et al., 2014), but the consequences of fungal-mediated $\mathrm{pH}$ changes for root growth and development have not yet been analyzed.

Here, we hypothesized that acidification may play an important role in the configuration of root architecture and phytostimulation elicited by Trichoderma. Through detailed characterization of the effects of several Trichoderma species on Arabidopsis seedling growth, the fungal capacity to acidify the growth medium, the effects of low $\mathrm{pH}$ stress on root growth and plant development, as well as testing the responses of selected Arabidopsis mutants defective on $\mathrm{pH}$ sensing, we demonstrate the critical role of fungal acidification as an early response influencing root morphogenesis and plant growth. Moreover, since lateral root initiation started earlier or in parallel to root tip bending and root stoppage, we propose that a low $\mathrm{pH}$ independent program operates at the root pericycle to induce root branching.

\section{MATERIALS AND METHODS}

\section{Plant Material and Growth Conditions}

All plants used in this study were in the Arabidopsis thaliana (L.) Heynh., Columbia (Col-0) background. Transgenic Arabidopsis lines DR5::GFP an auxin-inducible marker (Ottenschläger et al., 2003); H2B::YFP a cell viability marker (Boisnard-Lorig et al., 2001); WOX5:GFP a quiescent center (QC) marker in the root stem cell niche (SCN) (Sarkar et al., 2007); CycB1:uidA a marker of mitotic activity, expressed in the G2/M phase of the cell cycle (Colón-Carmona et al., 1999) previously characterized as well as the mutant stop1 known to show a hypersensitive root response to low $\mathrm{pH}$ (salk_114108) obtained from the Nottingham Arabidopsis Stock Centre (NASC), were used for the different experiments. Seeds were surface-disinfected with 95\% (v/v) ethanol for $5 \mathrm{~min}$ and $20 \%$ (v/v) bleach for $7 \mathrm{~min}$, washed five times with distilled water, and stratified for 2 days at $4^{\circ} \mathrm{C}$. Seeds were germinated and grown on agar plates containing 0.2X Murashige and Skoog (1962) medium (MS basal salts mixture, M524; PhytoTechnology), 0.6\% sucrose (Sucrose: Ultrapure, MB Grade, 21938; USB Corporation) and 1\% Agar (Agar, Micropropagation Grade, A111; PhytoTechnology) at $\mathrm{pH}$ 7. The suggested formulation is $4.3 \mathrm{~g}$. $\mathrm{L}^{-1}$ of salts for $1 \mathrm{x}$ medium; we used 0.9 g. $\mathrm{L}^{-1}$, which we consider and refer to as $0.2 \mathrm{X}$ MS. For MES (2-( $N$-morpholino)ethanesulfonic acid) treatments it was included in the plant growth medium and the $\mathrm{pH}$ was adjusted to 7.0. All experiments were performed in an environmentally controlled growth room with a $16 \mathrm{~h}$ photoperiod (300 $\mu \mathrm{mol} \mathrm{m} \mathrm{m}^{-2} \mathrm{~s}^{-1}$ of light intensity), and $22^{\circ} \mathrm{C}$.

\section{Fungal Strain and Culture Conditions}

Trichoderma atroviride IMI 206040 was propagated on potato dextrose agar (PDA; Difco), at $28^{\circ} \mathrm{C}$ for 5 days and then conidia were collected adding a small amount of sterile water into the Petri dishes and scraping the surface of the fungus. For the different experiments inoculation was carried out by placing a drop of a spore suspension containing $1 \times 10^{6}$ spores. In the interaction assays the Trichoderma inoculum was placed at $5 \mathrm{~cm}$ from $A$. thaliana primary roots germinated and grown for 5 days on agar plates containing 0.2X MS medium. The plates, which included $10 \mathrm{~A}$. thaliana seedlings each, were arranged in a completely randomized design. After 3 and 5 days of co-cultivation, plant growth was determined. For acidification experiments $T$. atroviride was inoculated on plates containing MS $0.2 \mathrm{X}$ supplied or not with bromophenol blue $(0.006 \%)$ and analyzed every $24 \mathrm{~h}$ for 4 days. 


\section{Analysis of Growth}

Growth of primary roots was registered using a ruler. Lateral root number was determined by counting the lateral roots present in the primary root from the tip to the root/stem transition. Images were recorded using a digital camera (Nikon D3300, Osaka, Japan). The length of meristems was determined as the distance from the QC to the cell file where cells started to elongate and measured using IMAGEJ software (National Institute of Health, Bethesda, MD, United States). All experiments were repeated at least twice as indicated in the figure legends and data analyzed in the STATISTICA 10 software (Stat Soft Inc, 2011). Univariate and multivariate analyses with a Tukey's post hoc test were used for testing differences in the experiments. Different letters are used to indicate means that differ significantly $(P \leq 0.05)$.

\section{Trichoderma Soluble Metabolites Experiments}

Trichoderma atroviride was inoculated on Petri plates containing MS $0.2 \mathrm{X}$ covered by a sterile cellophane sheet and incubated in darkness for the indicated times in the different experiments. The cellophane was removed together with the mycelium, then Arabidopsis seeds or seedlings were germinated or transferred, respectively, onto the plates where Trichoderma was pre-grown, and further grown for the indicated times.

\section{Propidium lodide Staining, GFP, and YFP Detection}

For confocal microscopy, transgenic A. thaliana seedlings cocultivated or not with Trichoderma were transferred from the growth medium to microscope slides with propidium iodide $(20 \mu \mathrm{M})$, used as counterstain. All imaging was done using a Zeiss LSM 510 META inverted confocal microscope (Carl Zeiss, Germany) with either a 20X or $40 \mathrm{X}$ objective. GFP was excited with a $488 \mathrm{~nm}$ line of an Argon laser and propidium iodide (PI) with a 514 laser line. GFP emission was filtered with a BP 500-520 nm filter and PI emission was filtered with a LP $575 \mathrm{~nm}$ filter, or by using a confocal microscope (Olympus FV1000; Olympus Corp., Tokyo, Japan), with a 568-nm wavelength argon laser for excitation, and an emission window of 585-610 nm for propidium iodide and GFP or YFP fluorescence $(488 \mathrm{~nm}$ excitation/505-550 nm emission, $514 \mathrm{~nm}$ excitation/527 nm emission, and $532 \mathrm{~nm}$ excitation/588 $\mathrm{nm}$ emission, respectively). Ten independent seedlings were analyzed per line, and treatment representative images were selected for figure construction.

\section{Histochemical Analysis of GUS Expression}

Histochemical $\beta$-glucuronidase (GUS) expression was evaluated by incubating the plant tissues in $0.1 \% \mathrm{X}$-Gluc (5-bromo4-chlorium-3-indolyl, $\beta$-D-glucuronide) phosphate buffer $\left(\mathrm{NaH}_{2} \mathrm{PO}_{4}\right.$ and $\mathrm{Na}_{2} \mathrm{HPO}_{4}, 0.1 \mathrm{M} ; \mathrm{pH}$ 7), $10 \mathrm{mM}$ EDTA, $0.1 \%$ (v/v) Triton X-100 with $2 \mathrm{mM}$ potassium ferrocyanide and $2 \mathrm{mM}$ potassium ferricyanide for $12 \mathrm{~h}$ at $37^{\circ} \mathrm{C}$. Plants were cleared and fixed using the method of Malamy and Benfey (1997). For each marker line and for each treatment, at least 15 transgenic plants were analyzed.

\section{Determination of Developmental Stages of Lateral Root Primordia (LRP)}

Lateral root primordia (LRP) were quantified 6 days after germination. Seedling roots were first cleared to enable LRP at early stages of development to be visualized and counted. Each LRP was classified according to its stage of development as reported by Malamy and Benfey (1997). The developmental stages are as follows. Stage I: LRP initiation (in the longitudinal plane, approximately eight to 10 'short' pericycle cells are formed). Stage II: the LRP are divided into two layers by a periclinal division. Stage III: the outer layer of the primordium divides periclinally, generating a three-layer primordium. Stage IV: an LRP with four cell layers. Stage V: the LRP are midway through the parent cortex. Stage VI: the LRP have passed through the parent cortex layer and has penetrated the epidermis. It begins to resemble the mature root tip. Stage VII: the LRP appear to be just about to emerge from the parent root.

\section{RESULTS}

\section{Early Root Responses during Arabidopsis Interaction with Trichoderma}

To study the early responses of Arabidopsis seedlings to Trichoderma, we performed time-course experiments of Arabidopsis seedlings co-cultured with $T$. atroviride. We found that in the early stages of the interaction, from 24 -to- $60 \mathrm{~h}$, primary root growth is unaffected (Figure 1A), and the meristem normally expresses $C y C B$ 1:uidA, a marker of mitotic activity, and the QC marker WOX5:GFP, whose corresponding WT protein is required to maintain the root SCN (Figure 1B). Nevertheless, T. atroviride clearly activated root branching at $60 \mathrm{~h}$ of the interaction (Figure 1C). The number of LRP per plant changed slightly at early stages of the interaction ( 24 and $48 \mathrm{~h}$ ). However, such differences were no longer observed after $60 \mathrm{~h}$ (Figure 1D), suggesting that the differences in root branching could be due to an accelerated growth of LRP in response to Trichoderma. This was evidenced by analyzing the LRP developmental stages, where a decrease in the number of LRP still at the early stages of development, particularly those at stages III and IV, and an increase in the number of those more developed (stage VII) and emerged lateral roots (ELR), as early as $24 \mathrm{~h}$ of co-cultivation was observed (Figure 1E). These data suggest that Trichoderma increases root branching in Arabidopsis mainly by inducing the maturation of LRP and not de novo formation of LRP, as an early response that occurs independently of primary root growth inhibition.

\section{Late Root Responses during Interaction with Trichoderma}

Early root responses of Arabidopsis to T. atroviride did not evidenced any negative effect. In agreement with a previous report (Contreras-Cornejo et al., 2009), we observed that T. atroviride promoted growth and development of lateral roots. However, after a longer time of interaction (72-96 h), a primary 


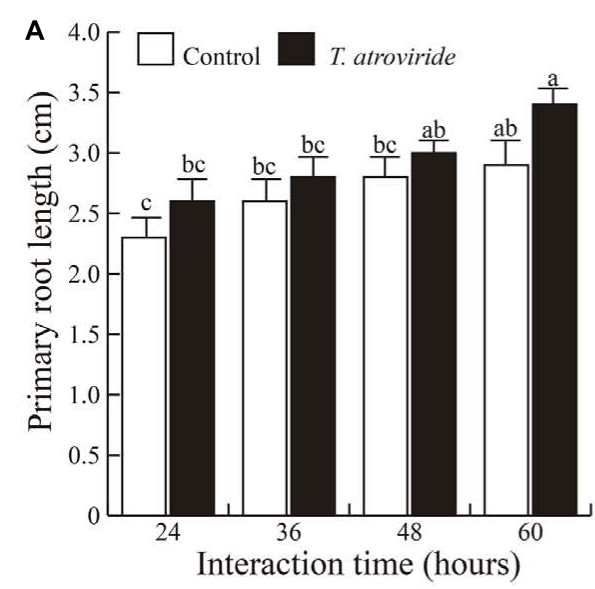

B
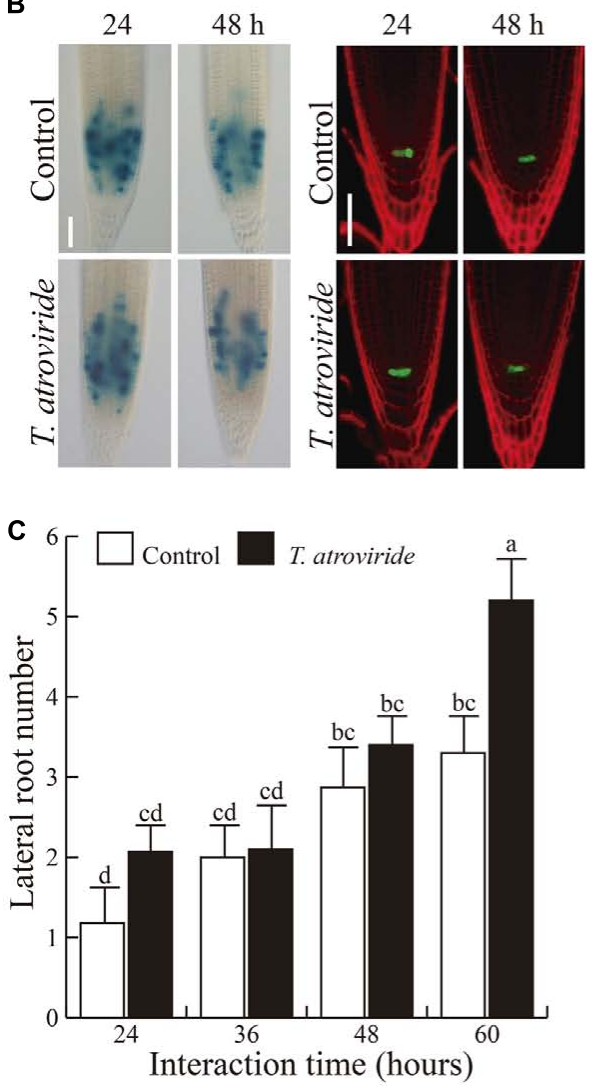

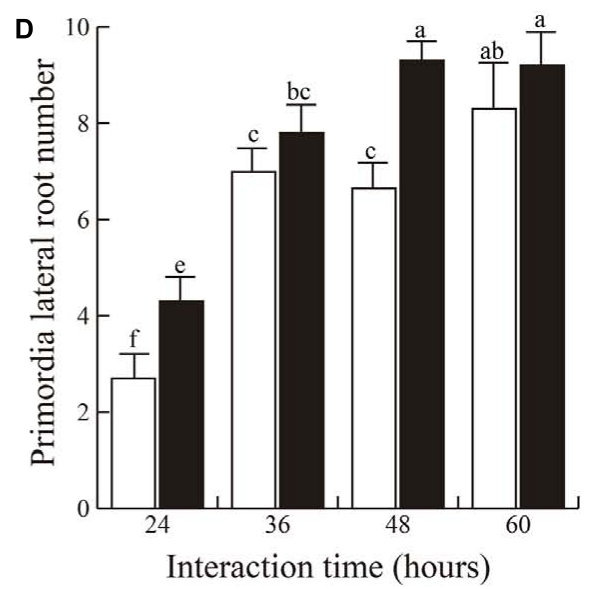

E
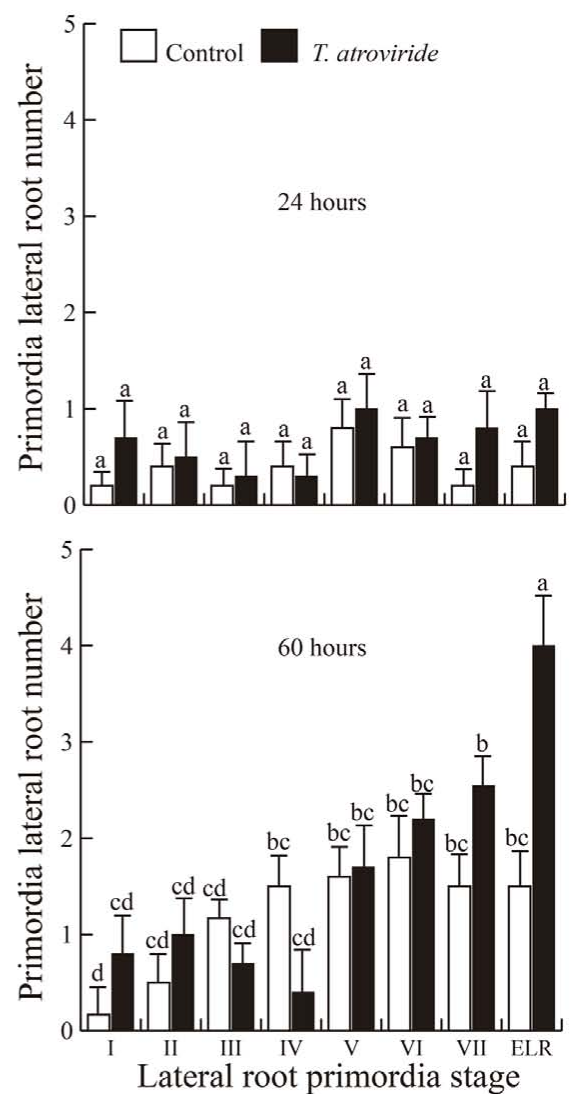

FIGURE 1 | Early responses of Arabidopsis to Trichoderma atroviride. Arabidopsis WT (Col-0) seeds were germinated and grown on agar solidified MS 0.2X medium. Four-day-old seedlings were inoculated with $1 \times 10^{6}$ spores of $T$. atroviride at the opposite side of where seeds were sown and analyzed at the indicated times. (A) Primary root length. (B) CyCB1:uidA (left) and WOX5:GFP (right) expression after 24 and $48 \mathrm{~h}$ of Trichoderma inoculation. (C) Lateral root number per plant. (D) Total lateral root primordia (LRP) per plant. (E) Number of LRP per plant after 24 and $60 \mathrm{~h}$ of interaction. Stage I: LRP initiation (in the longitudinal plane, approximately eight to 10 'short' pericycle cells are formed). Stage II: the LRP are divided into two layers by a periclinal division. Stage III: the outer layer of the primordium divides periclinally, generating a three-layer primordium. Stage IV: an LRP with four cell layers. Stage V: the LRP are midway through the parent cortex. Stage VI: the LRP have passed through the parent cortex layer and has penetrated the epidermis. It begins to resemble the mature root tip. Stage VII: the LRP appear to be just about to emerge from the parent root. Values shown represent means with SE of at least 30 seedlings. Different letters are used to indicate means that differ significantly $(P \geq 0.05)$. Scale bars $=50 \mu \mathrm{m}$. The experiment was repeated three times with similar results.

root growth inhibitory effect could be appreciated. Hence, we characterized in detail this late root response and its relationship with lateral root formation.
Inoculation with $T$. atroviride shortened primary roots (Figures 2A,C) while increasing lateral root number (Figures 2B,C). Surprisingly, the root tips bent forming a 

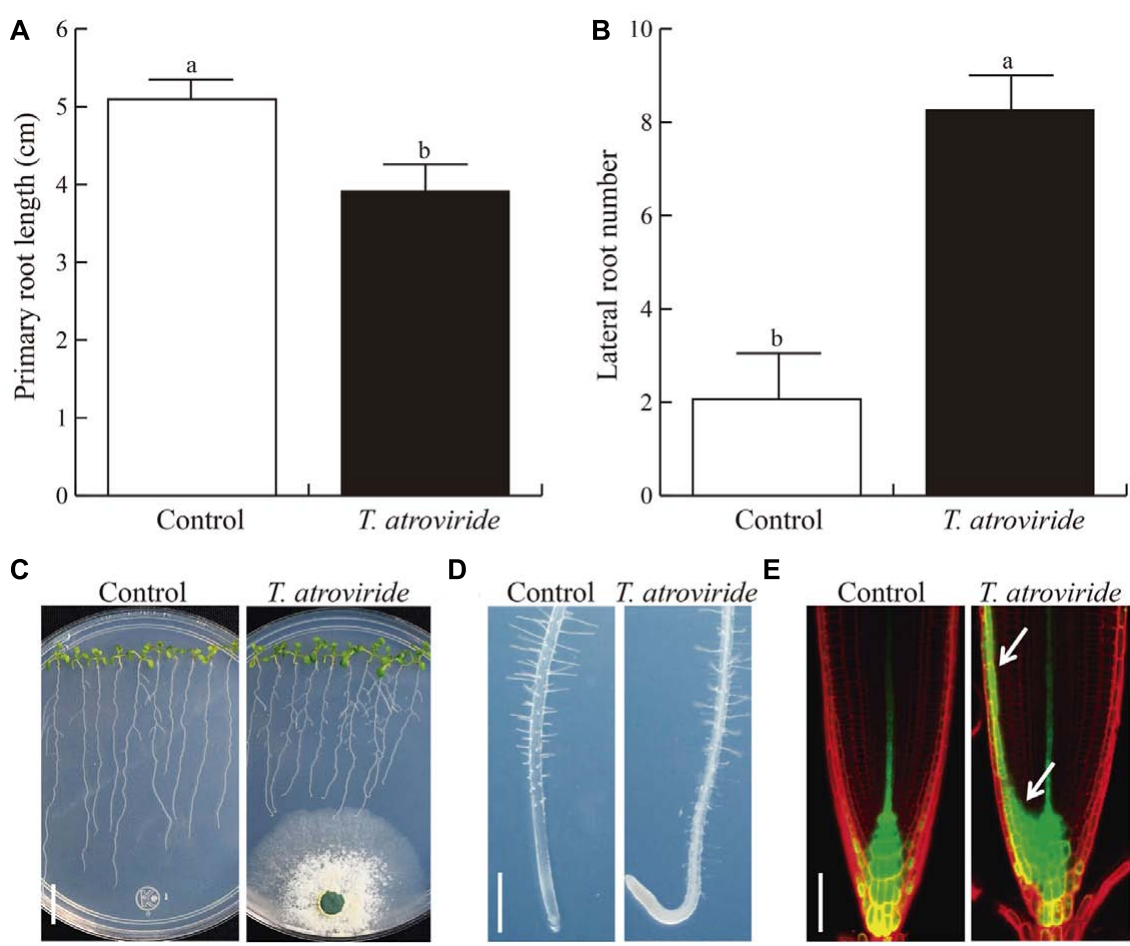

$\mathbf{E}$

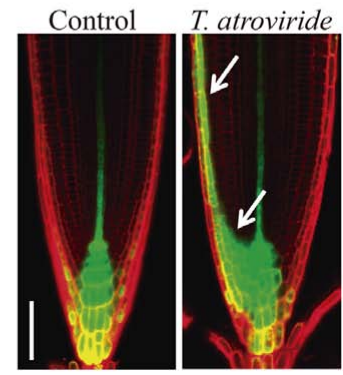

FIGURE 2 | Effects of $\boldsymbol{T}$. atroviride inoculation on Arabidopsis root architecture. (A) Primary root length. (B) Lateral root number. (C) Representative photographs of Arabidopsis seedlings co-cultivated with Trichoderma. (D) Root tips of axenic or Trichoderma co-cultivated WT seedlings, and DR5::GFP seedlings (E). White arrows show auxin redistribution. Arabidopsis seedlings were germinated and grown for 5 days on the surface of agar plates containing MS $0.2 X$ medium and then inoculated with $T$. atroviride at the opposite side of the plate and grown for 4 more days. Different letters are used to indicate means that differ significantly $(P<0.05)$. Error bars represents SE. Scale bars in images $(\mathbf{C}-\mathbf{E})=1 \mathrm{~cm}, 500$ and $50 \mu \mathrm{m}$, respectively. The experiment was repeated three times with similar results.

hook. The latter event is followed by inhibition of primary root elongation, stopping at the place where hook formation occurred, before contacting the mycelium (Figures 2C,D). Unexpectedly, upon prolonged interaction these responses were accompanied by pigmentation and chlorosis of leaves (Supplementary Figure S1). To investigate whether the bending response was specific to $T$. atroviride, we analyzed the root response to different Trichoderma species ( $T$. asperellum, T. koningii, and T. harzianum) and about 50 other native soil isolates. Interestingly, this response was similar, regardless of the Trichoderma species or isolate tested (representative images are shown in Supplementary Figure S2). These results suggest that a common signal released into the growth medium may be sensed by plants, thereof triggering the observed root responses.

To understand the signaling mechanisms involved in the elicited root bending response, and since Trichoderma was reported to produce auxins (Contreras-Cornejo et al., 2009), we analyzed the role of auxin signaling in this process. Like in the case of gravitational stimulation, an auxin- redistribution was observed in the root curvature response to T. atroviride, where auxins are redistributed within the root tip and accumulate on one side of the columella root cap cells, as indicated by the expression of the auxin-induced DR5:GFP marker (Figure 2E). This redistribution of auxin likely provokes a reduction of growth on one side of the root, which in turn could lead to the formation of the hook, or causes root growth reorientation. However, the observed redistribution of auxins did not explain the subsequent root growth inhibition, suggesting the involvement of additional fungal signals in root growth inhibition.

\section{T. atroviride Has a Strong Capacity to Acidify the Growth Medium}

Even though several studies have shown that $\mathrm{pH}$ is an important factor in fungal growth and development, little is known about the impact of fungal-mediated $\mathrm{pH}$ changes in root growth. Thus, we first determined the capacity of T. atroviride to modify the $\mathrm{pH}$ of the culture medium. For this purpose, we inoculated $1 \times 10^{6}$ spores in MS 0.2X medium supplemented with bromophenol blue, which is used as a $\mathrm{pH}$ indicator. We found that T. atroviride strongly acidifies the medium, which occurs at least in part through proton extrusion in a process that involves vanadate sensitive ATPases, since acidification was strongly reduced by adding increasing amounts of Sodium Orthovanadate (Vanadate, $\mathrm{Na}_{3} \mathrm{VO}_{4}$ ), a competitive inhibitor of plasma membrane ATPases (Figure 3). Therefore, media acidification by Trichoderma may explain the root bending response and thus, the primary root growth inhibition of Arabidopsis plants co-cultivated with T. atroviride described above. 


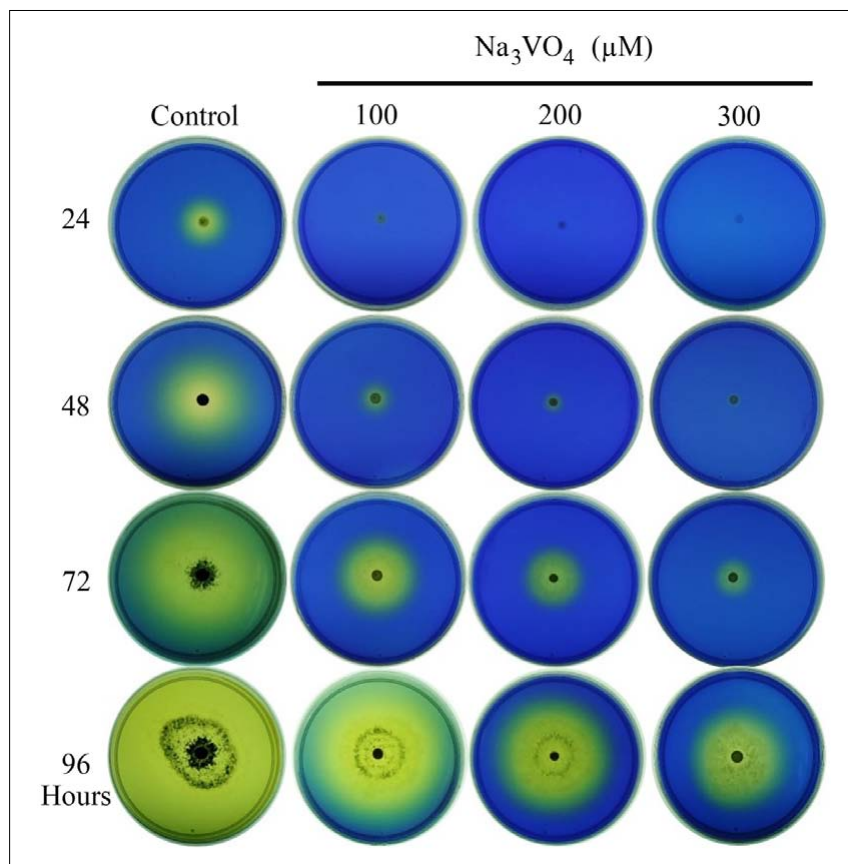

FIGURE 3 | Trichoderma induces acidification of the medium. T. atroviride was grown for the indicated times on MS 0.2X medium supplemented with bromophenol blue $\mathrm{pH}$ indicator and with or without vanadate at the indicated concentrations. Photographs show representative images of acidification by Trichoderma. The experiment was repeated twice with similar results.

\section{Acidification Induced by $T$. atroviride Strongly Represses the Arabidopsis Growth and Development}

To study the effect of Trichoderma induced-acidification on plant growth and development, Arabidopsis seeds or seedlings were sown or transferred, respectively, onto $0.2 \mathrm{X}$ MS growth medium where Trichoderma had grown. Interestingly, germination of Arabidopsis seeds sown on plates where Trichoderma had grown for $96 \mathrm{~h}$ was completely inhibited, in contrast with germination on control plates where all seeds germinated and seedlings developed normally (Figure 4A). Similar results were observed in Arabidopsis seedlings in transfer assays in which 4 days old Arabidopsis seedlings grown on MS $0.2 \mathrm{X}$ were transferred to control media or media where $T$. atroviride had been grown, and allowed to grow for 6 additional days. In this case, we observed that Arabidopsis primary root growth and overall plant development were inhibited in Trichodermatreated media, as compared with the continuing growth observed for control plants (Figures 4B,C). Moreover, when the experiment was repeated allowing Trichoderma to grow on a cellophane sheet for $18,24,30$, or $36 \mathrm{~h}$, we observed a gradual plant response. Evident inhibition was observed when plants were transferred onto media where Trichoderma had grown for $30 \mathrm{~h}$, and growth was completely inhibited six hours later (Supplementary Figure S3A). Similarly, Arabidopsis seed germination occurred when sown on media were Trichoderma had been grown for $30 \mathrm{~h}$ but growth stopped almost immediately, and no germination was observed by 36 h (Supplementary Figure S3B).

To determine if plant growth repression was indeed due to changes in the media conditions provoked by Trichoderma, we performed another experiment, in which T. atroviride was grown on un-buffered MS $(0.2 \mathrm{X})$ medium with initial $\mathrm{pH} 7$ on a side of the plates for $48 \mathrm{~h}$, time in which the growth medium has not been completely acidified by Trichoderma, and then Arabidopsis seeds were germinated and allowed to grow on the opposite side of the Petri dish. Interestingly, in seedlings that were grown under this condition, root growth orientation was affected, avoiding the area influenced by Trichoderma, compared with the normal vertical root growth of untreated seedlings (Supplementary Figure S3C). These results indicate that plants may sense the gradual changes in $\mathrm{pH}$ and adjust their root growth to escape from strongly acidic conditions.

\section{The Growth Repressing Effects of Trichoderma on Arabidopsis are Associated with Acidification}

All our findings on the root response of Arabidopsis to Trichoderma, were tightly correlated with the reported effects of low pH on plants (Koyama et al., 2001; Kang et al., 2013; Kobayashi et al., 2013). Thus, we evaluated the growth of plants in interaction with Trichoderma in $\mathrm{pH}$-buffered media. Under these conditions, primary root growth of Arabidopsis seedlings co-cultivated with Trichoderma was not inhibited at all, as compared to control plants without Trichoderma (Figure 5A). Moreover, lateral root emergence was strongly stimulated, with 7-8-fold more lateral roots than in plants without Trichoderma, which were also much longer than those in the control (Figures 5B,C). Similar results were obtained in experiments in which Arabidopsis seeds were directly germinated (Supplementary Figure S4) or seedlings transferred (Supplementary Figure S5) to buffered medium ( $\mathrm{pH} 7)$ where Trichoderma had been grown. Thus, buffering the medium eliminated the negative effects caused by Trichoderma on unbuffered media. In addition, we tested the toxic effects of low $\mathrm{pH}$ provoked by $T$. atroviride on Arabidopsis primary roots, to determine if it could be responsible for the observed growth inhibition. For this purpose, we analyzed cell viability by monitoring the expression of the $H 2 B:: Y F P$ reporter construct (Figure 6A), which is specifically expressed in the nuclei of living cells (Boisnard-Lorig et al., 2001), and by using a vital staining with propidium iodide, by confocal microscopy. Further, as root growth is maintained by the SCN, which includes cells of the QC in the root apical meristem (van den Berg et al., 1997; Bennett and Scheres, 2010), we also followed the status of the QC by monitoring the expression of the reporter construct WOX5:GFP (Figure 6B). Finally, we analyzed the expression of the cell division marker CyCB1:uidA (Figure 6C), which is expressed only in cells in the G2/M transition of the cell cycle in the primary root meristem (Colón-Carmona et al., 1999). In all cases, the expression of each reporter construct was lost in the primary root meristem of plants grown on unbuffered medium in the presence of Trichoderma, correlating 

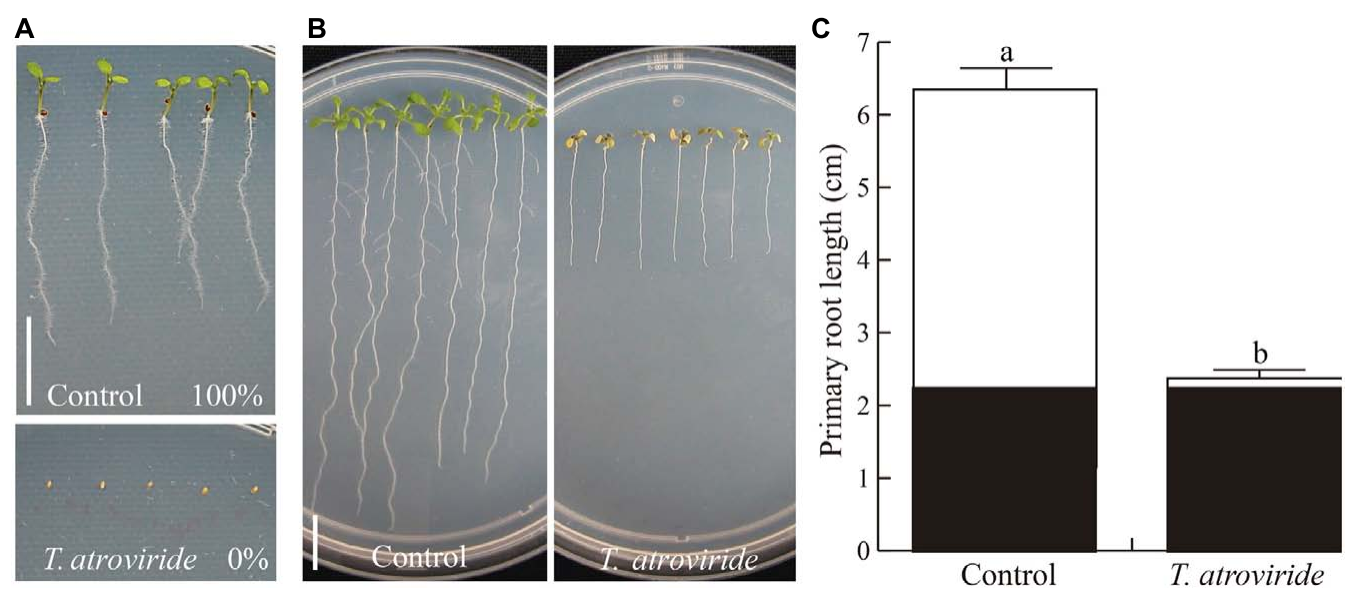

FIGURE 4 | Effects of acidification induced by $T$. atroviride on seed germination and growth of Arabidopsis plants. (A) Effect on germination. (B) Effect on growth of Arabidopsis seedlings. (C) Primary root length. In (A) Arabidopsis (Col-0) seeds were sown on medium MS 0.2X pH 7.0 (Control) or medium where Trichoderma had grown for 4 days (T. atroviride). In (B) Arabidopsis seedlings were first grown on control medium for 4 days and then transferred to the same growth conditions used in germination assays. Black bars in graph represent the root length at the time the plant was transferred and white bars the root length 6 days after transfer. Different letters indicate means that differ significantly $(P<0.05)$. Error bars represents SE. Scale bars $=1 \mathrm{~cm}$. The experiment was repeated three times with similar results.

with primary root growth inhibition (Figures 6A-C) and a clear $\mathrm{pH}$ drop (Figure 6D). Together, these data indicate that media acidification by $T$. atroviride strongly affects cell viability and cell division in primary roots, consequently impairing meristem functionality.

\section{Stop1 Response to T. atroviride Supports the Role of $\mathrm{pH}$ in the Plant-Trichoderma Communication}

The Arabidopsis mutant stop 1 (sensitive to proton rhizotoxicity 1) is well-known to be hypersensitive to low $\mathrm{pH}$ (Iuchi et al., 2007; Sawaki et al., 2009). Therefore, we evaluated whether stop1 was also oversensitive to $T$. atroviride or not. Interestingly, in the presence of Trichoderma, the primary root of the stop 1 mutant stopped growing much earlier than WT Arabidopsis seedlings (Figures 7A,B), but root bending was not observed (Figure 7B). It is likely that the root tip of the stop1 mutant could not bend or form a hook, because of its greater sensitivity to low $\mathrm{pH}$. Indeed, the primary root tip of the mutant showed clear signs of deterioration. This sensitivity was more clearly confirmed in two independent experiments in which T. atroviride had been grown for $27 \mathrm{~h}$ on the plant growth media supplied or not with MES buffer (Figure 8). As shown in Figure 8, primary root growth of the stop1 mutant was significantly reduced both at 10-dag (Figure 8A) and 3-days after transfer (dat) (Figure 8B). In both cases exposure to $T$. atroviride resulted in primary root growth similar to that observed at $\mathrm{pH}$ 4.7. In addition, we determined the effects of these treatments on cell division and elongation by measuring the primary root meristem size and length of fully developed cortical cells at the differentiation zone of 5 days old WT and stop1 Arabidopsis seedlings $48 \mathrm{~h}$ after transfer. Strong primary root growth inhibition of WT and stop 1 seedlings under low $\mathrm{pH}$ (4.7) and T. atroviride treatment correlated with smaller cortical cells and a smaller primary root meristem (Supplementary Figure S7). None of the negative effects caused by Trichoderma on the stop1 mutant on un-buffered media was observed when media was buffered with MES (Figure 8 and Supplementary Figure S6). The sensitivity of the stop1 mutant to Trichoderma indicates that the transcription factor STOP1 is involved in mediating the Arabidopsis root responses to media acidification by $T$. atroviride.

\section{DISCUSSION}

The beneficial effects of Trichoderma on plants such as stimulation of growth, nutrient uptake, induction of defense responses, and indirectly due to its mycoparasitic activity have been widely documented (Altomare et al., 1999; Benítez et al., 2004; Harman et al., 2004; Shoresh et al., 2010; ContrerasCornejo et al., 2013; López-Bucio et al., 2015). In this study, we show that Arabidopsis growth promotion is clearly observed during the early stages of the interaction and that acidification by Trichoderma plays an essential role in the Trichoderma-plant interaction.

Growth promotion effects of Trichoderma, reflected in root branching patterns and its correlation with plant biomass production have been studied to some extent but are not yet well understood. The participation of auxins in modulating these effects is supported by the induction of the expression of the auxin-inducible marker gene DR5:uidA in roots and shoots of WT plants and by the reduced response of Arabidopsis mutants affected in auxin transport or signaling to Trichoderma virens (Contreras-Cornejo et al., 2009). Although Trichoderma produces auxins and other diffusible compounds, which may modulate plant growth and development, the whole phytostimulation program may not solely or completely be 

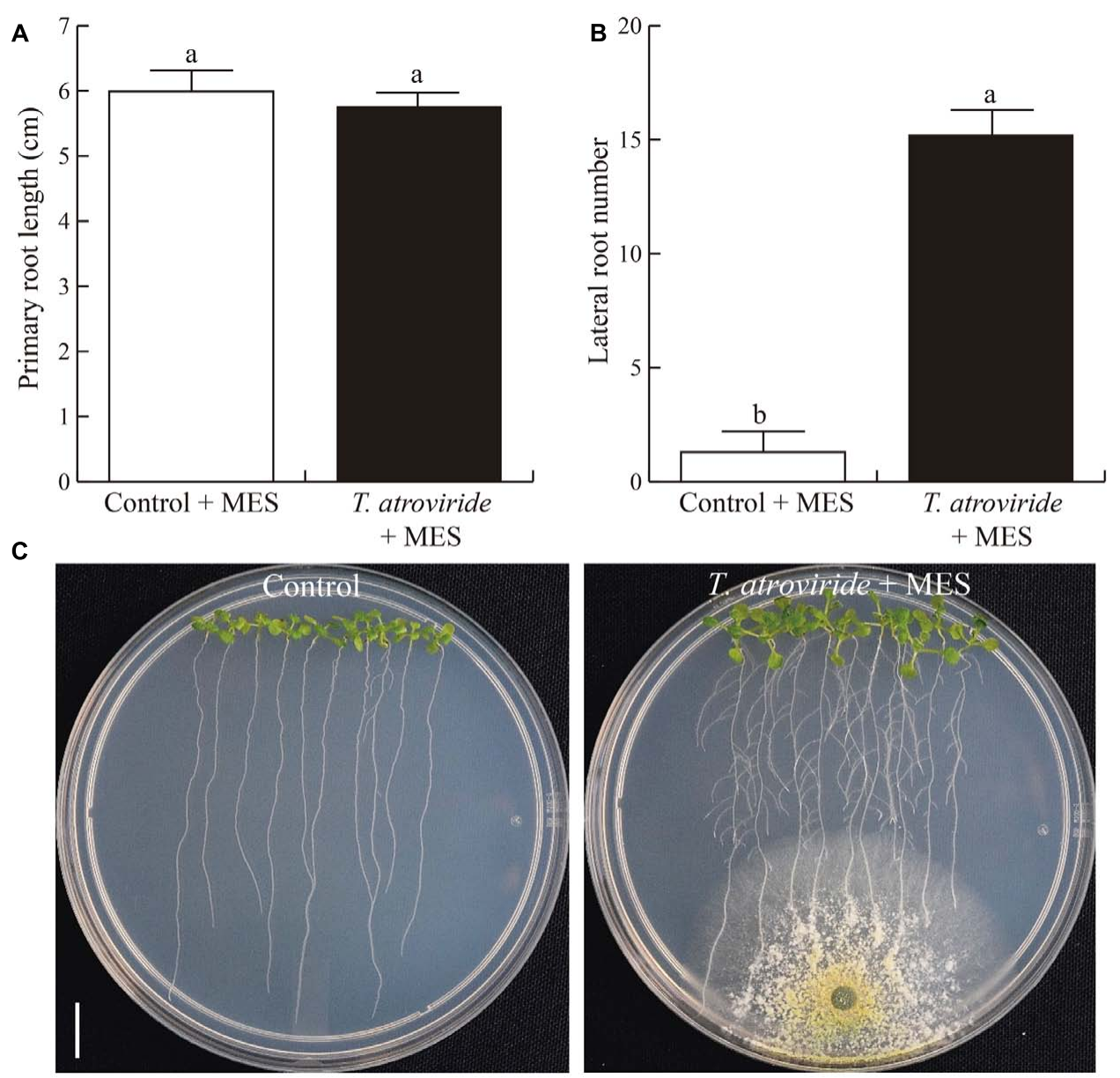

FIGURE 5 | Effects of $\boldsymbol{T}$. atroviride inoculation on Arabidopsis growth under buffered medium. (A) Primary root length. (B) Lateral root number.

(C) Representative photographs of Arabidopsis seedlings co-cultivated with Trichoderma. Arabidopsis seedlings were germinated and grown on MS $0.2 \mathrm{X}$ medium buffered with MES $0.12 \%$, after 5 days T. atroviride was inoculated at the opposite side of the plate and grown for 4 additional days. Different letters are used to indicate means that differ significantly $(P<0.05)$. Error bars represents SE. Scale bar $=1 \mathrm{~cm}$. The experiment was repeated three times with similar results.

explained by an auxinic mechanism, since IAA production is strain dependent and can be affected by diverse external stimuli (Nieto-Jacobo et al., 2017). Furthermore, some Trichoderma strains inhibit the auxinic root response of Arabidopsis primary roots (Nieto-Jacobo et al., 2017). In this regard, recent findings suggest that growth promotion induced by Trichoderma during the early plant-Trichoderma interaction stages could be attributed mostly to volatile organic compounds (VOCs) more than to the release of auxins or other diffusible compounds by the fungus. Exposure of plants to VOCs of different Trichoderma species have been found to stimulate plant growth, chlorophyll content, and plant size and biomass, which could be correlated with an enhanced soil exploratory capacity, better rooting and an enhanced capacity to take up nutrients and water (Hung et al., 2013; Contreras-Cornejo et al., 2014b; Lee et al., 2016; Nieto-Jacobo et al., 2017). It is noteworthy, that we found that longer interaction times with Trichoderma had clear detrimental effects on primary roots compared with untreated plants, such as root tip bending and growth inhibition, which correlate with anthocyanin-like pigmentation of leaves and the eventual development of leaf chlorosis. Anthocyanin production in leaves has been found to occur as consequence or parallel effect of plant defense induction in response to Trichoderma (ContrerasCornejo et al., 2011). Based on our findings, we suggest that anthocyanin accumulation could be related with a plant response to acidification by Trichoderma rather than to the induction of the plant defense response.

Rhizosphere acidification by Trichoderma spp. particularly Trichoderma harzianum strain $\mathrm{T}-22$, has been reported in a couple of studies, one of them performed by Altomare et al. (1999), which investigated the fungal capacity to solubilize, in vitro, insoluble or sparingly soluble minerals by acidification of the medium. In their report the authors indicated that Trichoderma acidified the medium, but concluded that acidification was not the major mechanism of solubilization of insoluble minerals. Similarly, Sofo et al. (2012) found that T. harzianum T22 acidified the growth medium and that this may account for its beneficial effects on plants under hostile growth 


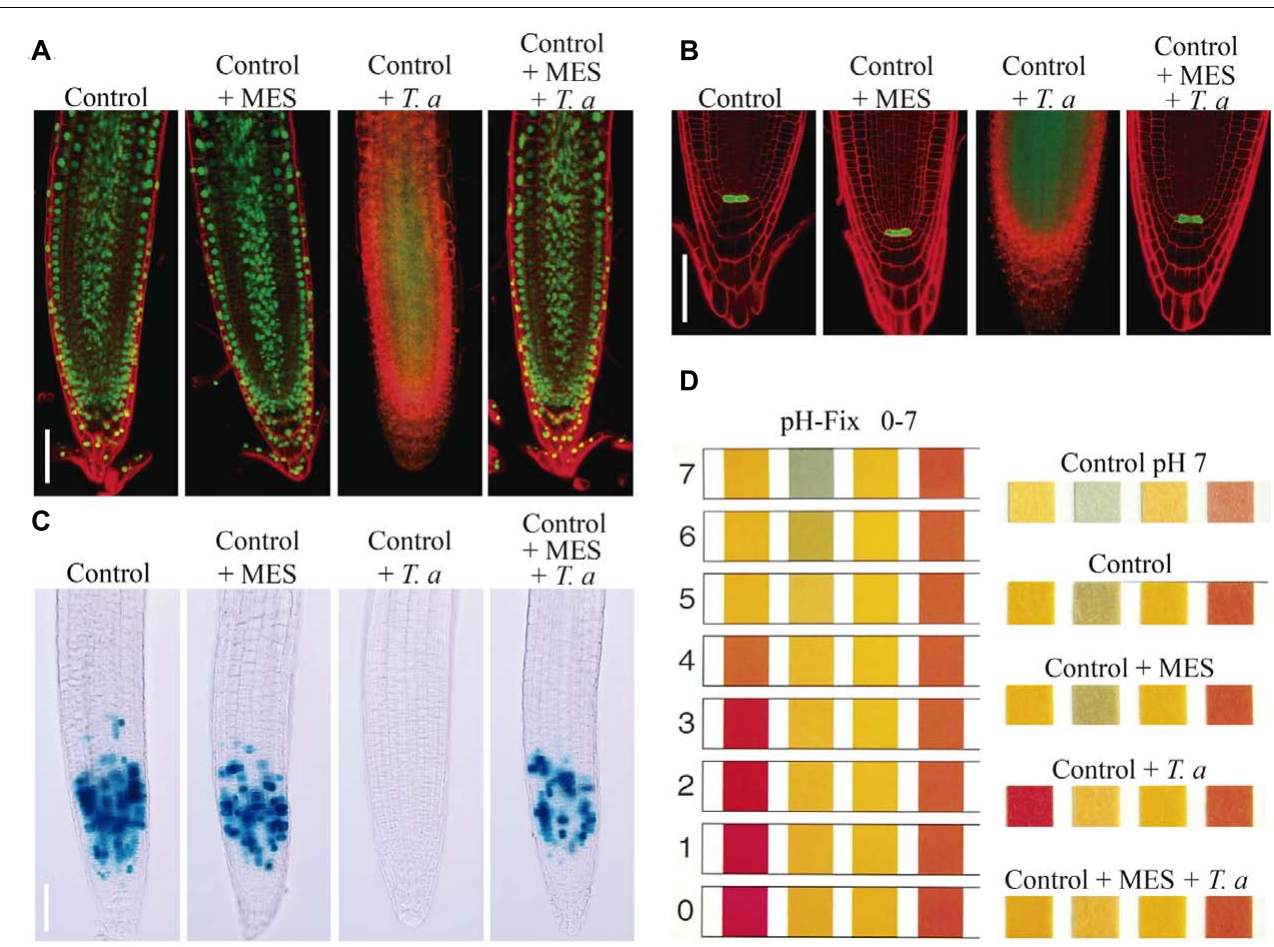

FIGURE 6 | Acidification induced by $\mathbf{T}$. atroviride impairs the Arabidopsis root meristem functionality. (A) Expression of vital marker H2B::YFP (B) Expression of the root quiescent center (QC) marker WOX5:GFP. (C) Expression of the cell division marker CycB1:uidA. (D) Estimated pH on the different growth conditions. Five-day-old seedlings of different transgenic lines used were transferred to the indicated treatments and analyzed $24 \mathrm{~h}$ later. Photographs show representative images of at least 10 seedlings analyzed per experiment. Scale bars $=50 \mu \mathrm{m}$. These experiments were repeated twice with similar results.
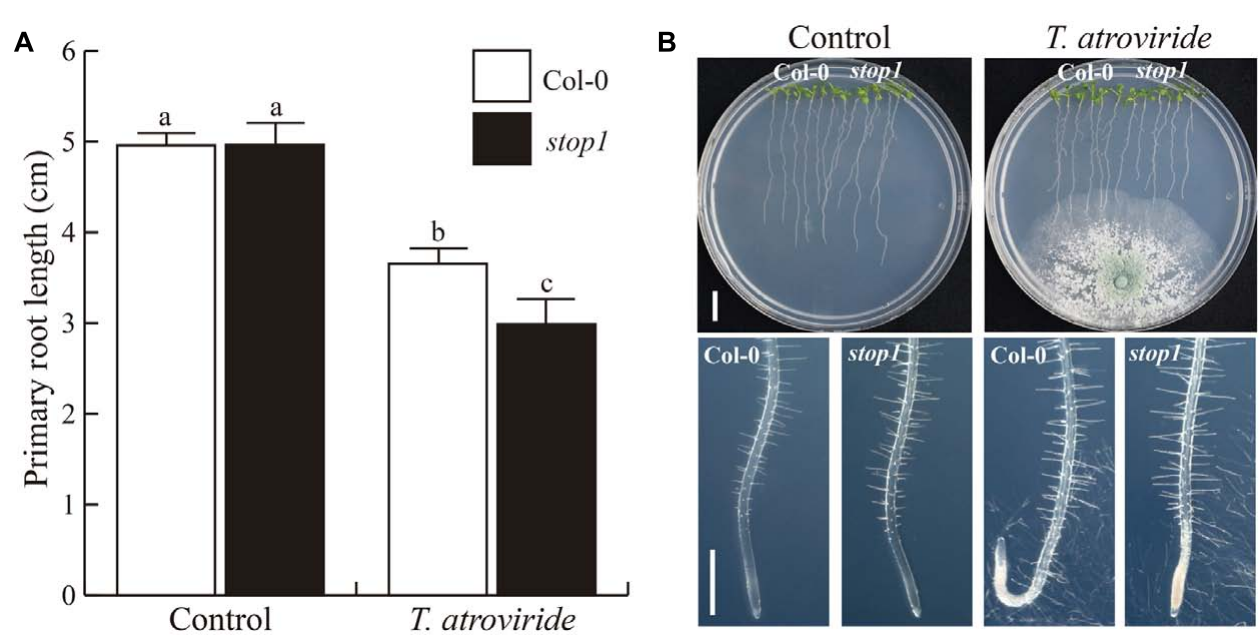

FIGURE 7 | Effect of T. atroviride on growth of Arabidopsis WT and stop1 mutants. (A) Six-day-old A. thaliana WT seedlings and stop1 mutant were co-cultivated with $1 \times 10^{6}$ spores of $T$. atroviride, by placing the fungus on the opposite side of the Petri plate, where seeds were sown. (A) Effect on primary root length. (B) Photographs of WT and stop1 seedlings. Different letters indicate means statistically different at $P<0.05$. Error bars represents SE. Scale bars $=1 \mathrm{~cm}$ and $500 \mu \mathrm{m}$. This experiment was repeated three times with similar results.

conditions. More recently, medium acidification by T. atroviride and $T$. virens was also observed in co-cultivation experiments with Arabidopsis, a phenomenon that was correlated with the plant promoting effects exerted by Trichoderma on Arabidopsis seedlings (Contreras-Cornejo et al., 2016).
It is known that plants can naturally acidify the rhizosphere to improve nutrient availability or uptake, and this may be particularly relevant in alkaline calcareous soils in which phosphate and iron are very limiting, but only a slight acidification can be beneficial for plant growth and development 

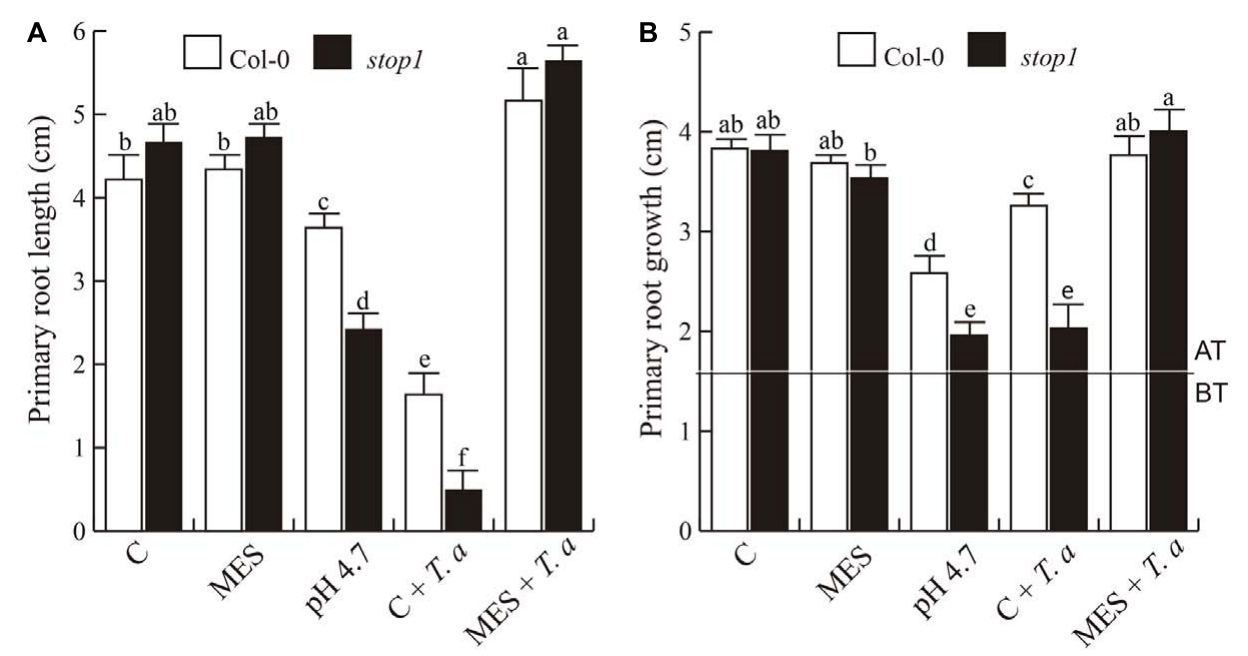

FIGURE 8 | Sensitivity of stop1 to acidification induced by $\mathbf{T}$. atroviride. (A,B) Primary root length. (A) Seeds were germinated and grown directly under the indicated conditions or (B) on a pH 7.0 medium for 4 days and then transferred to the indicated treatments and analyzed 3 days after transfer. BT and AT in graph (B) indicate the root growth before and after transfer, respectively. Different letters in graphic indicate means statistically different at $P<0.05$. This experiment was repeated twice with similar results.

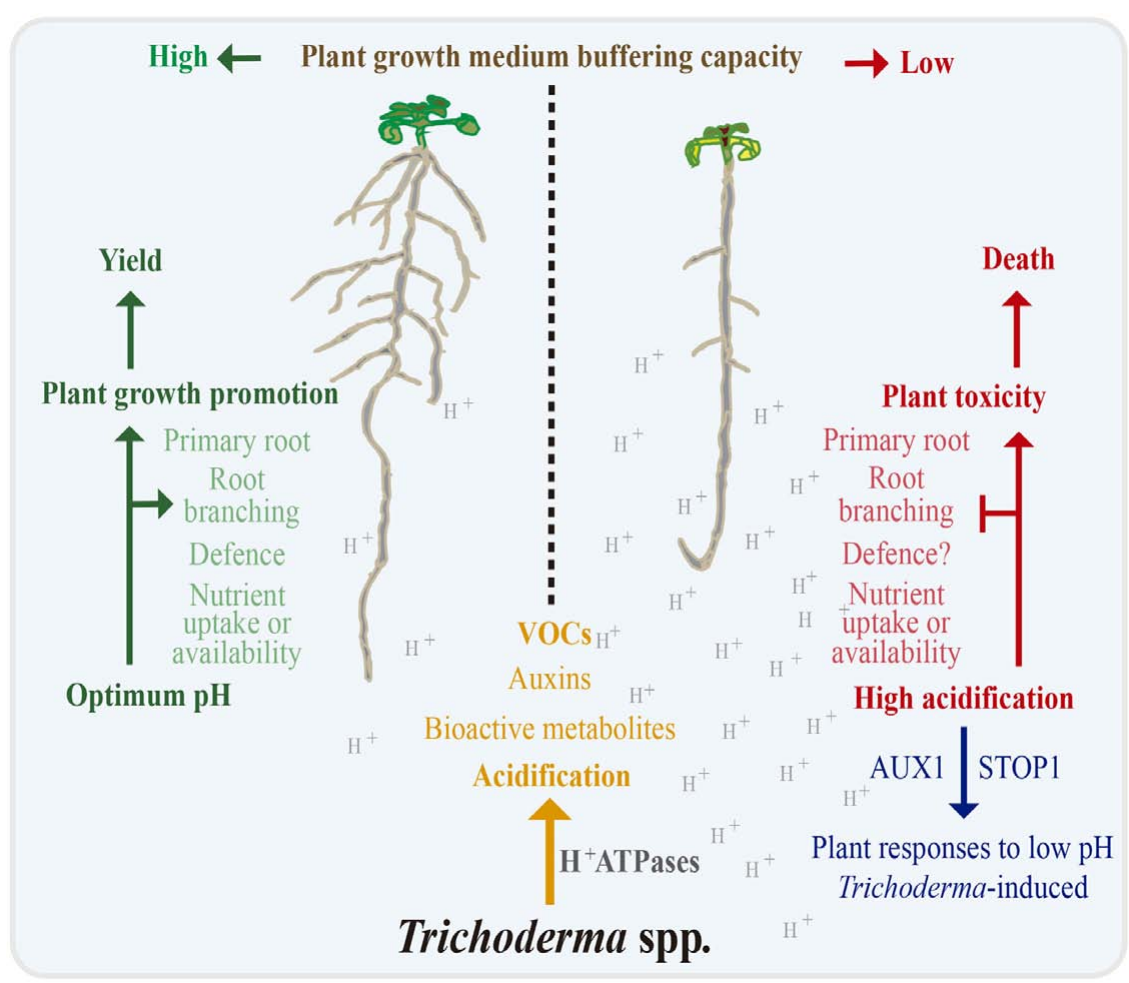

FIGURE 9 | Model for the interaction of Trichoderma with plants. Rhizosphere acidification by Trichoderma together with auxins, VOCs, and other bioactive molecules reconfigure root architecture and may promote or impair plant growth depending upon soil pH conditions. STOP1 and AUX1 likely act in a root pH sensing pathway to adapt the root system to the acidification likely via lateral root production.

in soils with neutral or slightly acid pHs (Marschner, 1991; Hinsinger et al., 2003), while strong acidification negatively affects plant growth. Here, we found that T. atroviride strongly acidified the medium, through a process mediated at least in part by $\mathrm{H}^{+}$-ATPases, because the addition of sodium orthovanadate $\left(\mathrm{Na}_{3} \mathrm{VO}_{4}\right)$, an ATPase inhibitor reduced acidification in a dosedependent manner. Our data indicate that media acidification by Trichoderma has a clear detrimental effect on Arabidopsis, 
affecting plant development, from seed germination to root and shoot growth. These findings are consistent with the effects of low $\mathrm{pH}$ reported in various studies, where acidity was found to affect Arabidopsis root growth (Koyama et al., 1995, 2001; Kang et al., 2013), and inhibit seed germination of different plants (Fan and Li, 1999; Zeng et al., 2005). Thus, the inhibitory effects observed on Arabidopsis seedlings in co-cultivation with T. atroviride may be explained by a high level of acidification. Furthermore, when the Arabidopsis-Trichoderma experiments were carried out under buffered conditions, a clear increase in growth promotion by Trichoderma was observed, and the negative effects (i.e., germination and growth inhibition) were negligible, restoring completely plant growth. These results correlated with the expression of different markers used to test root meristem functionality as well as with $\mathrm{pH}$ levels observed under the different growth conditions. Similar detrimental effects on Arabidopsis root growth were recently reported for certain Trichoderma strains (Nieto-Jacobo et al., 2017). Although, the authors associated this response with an impaired auxin signaling, in our view, root growth repression may rather be a consequence of loss of root meristem functionality caused by acidification.

Low $\mathrm{pH}$ stress is related with $\mathrm{Al}$ toxicity, because at low $\mathrm{pH}$ the highly toxic $\mathrm{Al}^{3+}$ severely affects plant growth. However, increasing evidence supports that toxic $\mathrm{H}^{+}$and $\mathrm{Al}^{3+}$ elicit different adaptive mechanisms in plants (Shavrukov and Hirai, 2016). In bacteria and fungi, different $\mathrm{pH}$-signaling pathways have been identified (Arst and Peñalva, 2003; Yuan et al., 2008), but in plants no specific mechanisms for $\mathrm{pH}$ sensing have been reported. The transcription factor STOP1 is one of the very few regulators of gene expression in plant responses to $\mathrm{Al}^{3+}$ and low pH stress (Iuchi et al., 2007; Sawaki et al., 2009). Accordingly, we found that the Arabidopsis mutant stop1 showed higher root growth repression when co-cultivated with Trichoderma than WT seedlings, evidenced by a shorter primary root and absence of root bending or hook in the root tip. Such oversensitivity was confirmed in experiments where the WT and the stop 1 mutants were grown in medium supplemented with MES buffer, in which Trichoderma had been grown, supporting a role of $\mathrm{pH}$ as a signal in the interaction of Trichoderma with plants. Taken together, these results suggest that the $\mathrm{pH}$ status could be sensed by roots to activate a signaling cascade that modulates root growth and its orientation, and possibly, to activate lateral root initiation.

A recent report demonstrated that the inhibitory effects of low $\mathrm{pH}$ on root growth are mediated by an adaptive plant response rather than by a direct toxic effect of $\mathrm{H}^{+}$, because direct root exposure to low $\mathrm{pH}$, suppressed root growth and caused high cell death, while roots exposed gradually to the low $\mathrm{pH}$ stress stopped growth but maintained cell viability (Graças et al., 2016). Although the molecular components mediating the root responses to $\mathrm{pH}$ or their possible link with auxin signaling are currently unknown, the idea of $\mathrm{pH}$ as a signal in plantmicrobe interactions is supported by global gene expression analyses, which showed that low $\mathrm{pH}$ alters the expression of genes related to auxin signaling, pathogen elicitors, and defenseassociated hormones. It is possible that $\mathrm{pH}$-sensing and $\mathrm{Ca}^{2+}$ signaling may be mediated by proton effects on inward rectifying
$\mathrm{K}^{+-}$channels or via a $\mathrm{pH}$ specific sensor (Lager et al., 2010). The fact that the Arabidopsis aux1-7 mutant is hypersensitive to low $\mathrm{pH}$, suggests an important role of auxin transport in root growth response to acidification (Inoue et al., 2016), and since the same mutant had a reduced response to $T$. virens inoculation in terms of shoot biomass production and lateral root development (Contreras-Cornejo et al., 2009), we propose that normal auxin transport is important for plant growth and root adaptation to low $\mathrm{pH}$ following Trichoderma inoculation. In addition, the nitrate transporters NRT1.1 and OsNRT2.3b are involved in $\mathrm{H}^{+}$ resistance in Arabidopsis and rice, respectively, a phenomenon that depends on their nitrate uptake activity (Fang et al., 2016; Fan et al., 2016b). The relationship of Trichoderma with nitrate nutrition of plants represents an interesting research avenue to follow.

\section{CONCLUSION}

This report provides compelling evidence that root sensing of $\mathrm{pH}$ mediates the interaction of Trichoderma with plants. Rhizosphere acidification by Trichoderma may influence the root developmental response to auxins, VOCs, and other bioactive molecules and stimulate or repress different plant processes in a plant specific manner and depending upon the soil characteristics (Figure 9). We have further identified STOP1 as a critical factor in mediating root adaptation to fungal-induced acidification, which might act in a pathway involving auxin signaling and transport, where AUX1 links acidity to growth responses and plant adaptation to $\mathrm{H}^{+}$stress. These data may help in the management of Trichoderma based strategies for crop improvement, and may aid in the identification of more efficient Trichoderma-strains for their use in bio-fertilizers or bio-inoculant formulation to increase plant growth and yield.

\section{AUTHOR CONTRIBUTIONS}

RP-F designed and performed experiments, collected, and interpreted data; AG-V performed experiments; SE-R performed experiments and provided technical support; JL-B and AH-E: designed experiments and contributed to data interpretation. RP-F, JL-B, and AH-E wrote the manuscript.

\section{FUNDING}

This work was financially supported by a grant from SEPCONACYT (236825). RP-F is indebted to the Consejo Nacional de Ciencia y Tecnología (CONACYT) for a postdoctoral fellowship.

\section{ACKNOWLEDGMENTS}

José Irepan Reyes-Olalde and León Francisco Ruíz Herrera are gratefully acknowledged for technical support for confocal 
microscopy analysis. We are also grateful to José Pedro Martínez Hernández for his kind technical support for Trichoderma management and Stefan de Folter for helpful advice. We thank Javier Mora-Macías and the Nottingham Arabidopsis Stock Centre (NASC) for providing Arabidopsis seeds.

\section{REFERENCES}

Alkan, N., Espeso, E. A., and Prusky, D. (2013). Virulence regulation of phytopathogenic fungi by $\mathrm{pH}$. Antioxid. Redox Signal. 19, 1012-1025. doi: 10.1089/ars.2012.5062

Altomare, C., Norvell, W. A., Bjorkman, T., and Harman, G. E. (1999). Solubilization of phosphates and micronutrients by the plant-growthpromoting and biocontrol fungus Trichoderma harzianum Rifai 1295-22. Appl. Environ. Microbiol. 65, 2926-2933.

Arst, H. N., and Peñalva, M. A. (2003). pH regulation in Aspergillus and parallels with higher eukaryotic regulatory systems. Trends Genet. 19, 224-231. doi: 10.1016/S0168-9525(03)00052-0

Benítez, T., Rincón, A. M., Limón, M. C., and Codón, A. C. (2004). Biocontrol mechanisms of Trichoderma strains. Int. Microbiol. 7, 249-260.

Bennett, T., and Scheres, B. (2010). Root development-two meristems for the price of one? Curr. Top. Dev. Biol. 91, 67-102. doi: 10.1016/S0070-2153(10)91003-X

Boisnard-Lorig, C., Colon-Carmona, A., Bauch, M., Hodge, S., Doerner, P., Bancharel, E., et al. (2001). Dynamic analyses of the expression of the HISTONE:YFP fusion protein in Arabidopsis show that syncytial endosperm is divided in mitotic domains. Plant Cell. 13, 495-509. doi: 10.1105/tpc.13.3.495

Brady, N. C., and Weil, R. R. (1999). In "Nature and Properties of Soils." Upper Saddle River, NJ: Prentice-Hall.

Brady, N. C., and Weil, R. R. (2010). Elements of the Nature and Properties of Soils. Hoboen, NJ: Pearson Education International.

Colón-Carmona, A., You, R., Haimovitch-Gal, T., and Doermer, P. (1999). Spatiotemporal analysis of mitotic activity with a labile cyclin-GUS fusion protein. Plant J. 20, 503-508. doi: 10.1046/j.1365-313x.1999.00620.x

Contreras-Cornejo, H. A., López-Bucio, J. S., Méndez-Bravo, A., MacíasRodríguez, L., Ramos-Vega, M., Guevara-García, A., et al. (2015). Mitogenactivated protein kinase 6 and ethylene and auxin signaling pathways are involved in Arabidopsis root-system architecture alterations by Trichoderma atroviride. Mol. Plant-Microbe Interact. 28, 701-710. doi: 10.1094/MPMI-0115-0005-R

Contreras-Cornejo, H. A., Macías-Rodríguez, L. I., Alfaro-Cuevas, R., and LópezBucio, J. (2014a). Trichoderma spp. improve growth of Arabidopsis seedlings under salt stress through enhanced root development, osmolite production, and $\mathrm{Na}+$ elimination through root exudates. Mol. Plant-Microbe Interact. 27, 503-514. doi: 10.1094/MPMI-09-13-0265-R

Contreras-Cornejo, H. A., Macías-Rodríguez, L., Beltrán-Peña, E., HerreraEstrella, A., and López-Bucio, J. (2011). Trichoderma-induced plant immunity likely involves both hormonal and camalexin-dependent mechanisms in Arabidopsis thaliana and confers resistance against necrotrophic fungi Botrytis cinerea. Plant Signal. Behav. 6, 1554-1563. doi: 10.4161/psb.6.10.17443

Contreras-Cornejo, H. A., Macias-Rodriguez, L., del-Val, E., and Larsen, J. (2016). Ecological functions of Trichoderma spp. and their secondary metabolites in the rhizosphere: interactions with plants. FEMS Microbiol. Ecol. 92:fiw036. doi: 10.1093/femsec/fiw036

Contreras-Cornejo, H. A., Macías-Rodríguez, L. I., Cortés-Penagos, C., and López-Bucio, J. (2009). Trichoderma virens, a plant beneficial fungus, enhances biomass production and promotes lateral root growth through an auxin-dependent mechanism in Arabidopsis. Plant Physiol. 149, 1579-1592. doi: 10.1104/pp.108.130369

Contreras-Cornejo, H. A., Macías-Rodríguez, L. I., Herrera-Estrella, A., and LópezBucio, J. (2014b). The 4-phosphopantetheinyl transferase of Trichoderma virens plays a role in plant protection against Botrytis cinerea through volatile organic compound emission. Plant Soil. 379, 261-274. doi: 10.1007/s11104-014-2069-x

Contreras-Cornejo, H. A., Ortiz-Castro, R., and López-Bucio, J. (2013). "Promotion of plant growth and the induction of systemic defence by Trichoderma: physiology, genetics and gene expression," in Trichoderma:

\section{SUPPLEMENTARY MATERIAL}

The Supplementary Material for this article can be found online at: http://journal.frontiersin.org/article/10.3389/fpls.2017.00822/ full\#supplementary-material

Biology and Applications, eds P. K. Mukherjee, B. A. Horwitz, U. S. Singh, M. Mukherjee, and M. Schmoll (Walingford: CABI), 173-194.

Druzhinina, I. S., Seidl-Seiboth, V., Herrera-Estrella, A., Horwitz, B. A., Kenerley, C. M., Monte, E., et al. (2011). Trichoderma: the genomics of opportunistic success. Nat. Rev. Microbiol. 9, 749-759. doi: 10.1038/nrmicro2637

Fan, H. B., and Li, C. R. (1999). Effects of simulated acid rain on seedling emergence and growth of five broad-leaved species. J. For. Res. 10, 83-86. doi: 10.1007/ BF02855532

Fan, W., Lou, H. Q., Yang, J. L., and Zheng, S. J. (2016a). The roles of STOP1-like transcription factors in aluminum and proton tolerance. Plant Signal. Behav. 11:e1131371. doi: 10.1080/15592324.2015.1131371

Fan, X., Tang, Z., Tan, Y., Zhang, Y., Luo, B., Yang, M., et al. (2016b). Overexpression of a $\mathrm{pH}$-sensitive nitrate transporter in rice increases crop yields. Proc Natl. Acad. Sci. U.S.A. 113, 7118-7123. doi: 10.1073/pnas. 1525184113

Fang, X. Z., Tian, W. H., Liu, X. X., Lin, X. Y., Jin, C. W., and Zheng, S. J. (2016). Alleviation of proton toxicity by nitrate uptake specifically depends on nitrate transporter 1.1 in Arabidopsis. New Phytol. 211, 149-158. doi: 10.1111/nph. 13892

Garnica-Vergara, A., Barrera-Ortiz, S., Muñoz-Parra, E., Raya-González, J., Méndez-Bravo, A., Macías-Rodríguez, L., et al. (2016). The volatile 6-pentyl2H-pyran-2-one from Trichoderma atroviride regulates Arabidopsis thaliana root morphogenesis via auxin signaling and ETHYLENE INSENSITIVE 2 functioning. New Phytol. 209, 1496-1512. doi: 10.1111/nph.13725

Graças, J. P., Ruiz-Romero, R., Figueiredo, L. D., Mattiello, L., Peres, L. E. P., and Vitorello, V. A. (2016). Root growth restraint can be an acclimatory response to low $\mathrm{pH}$ and is associated with reduced cell mortality: a possible role of class III peroxidases and NADPH oxidases. Plant Biol. 18, 658-668. doi: 10.1111/plb. 12443

Harman, G. E. (2006). Overview of mechanisms and uses of Trichoderma spp. Phytopathology. 96, 190-194. doi: 10.1094/PHYTO-96-0190

Harman, G. E., Howell, C. R., Viterbo, A., Chet, I., and Lorito, M. (2004). Trichoderma species-opportunistic, avirulent plant symbionts. Nat. Rev. Microbiol. 2, 43-56. doi: 10.1038/nrmicro797

Hashem, A., Allah, E. F., Alqarawib, A. A., Al Huqaila, A., and Egamberdieva, D. (2014). Alleviation of abiotic salt stress in Ochradenus baccatus (Del.) by Trichoderma hamatum (Bonord.) Bainier. J. Plant Interact. 9, 857-868. doi: 10.1080/17429145.2014.983568

Hermosa, R., Viterbo, A., Chet, I., and Monte, E. (2012). Plant-beneficial effects of Trichoderma and of its genes. Microbiology 158, 17-25. doi: 10.1099/mic.0. 052274-0

Hinsinger, P., Plassard, C., Tang, C., and Jaillard, B. (2003). Origins of rootmediated $\mathrm{pH}$ changes in the rhizosphere and their responses to environmental constraints: a review. Plant Soil. 248, 43-59. doi: 10.1023/A:1022371130939

Hung, R., Lee, S., and Bennett, J. W. (2013). Arabidopsis thaliana as a model system for testing the effects of Trichoderma volatile organic compounds. Fungal Ecol. 6, 19-26. doi: 10.1016/j.funeco.2012.09.005

Husson, O. (2013). Redox potential (Eh) and $\mathrm{pH}$ as drivers of soil/plant/microorganism systems: a transdisciplinary overview pointing to integrative opportunities for agronomy. Plant Soil 362, 389-417. doi: 10.1007/s11104-012-1429-7

Inoue, S. I., Takahashi, K., Okumura-Noda, H., and Kinoshita, T. (2016). Auxin influx carrier AUX1 confers acid resistance for Arabidopsis root elongation through the regulation of plasma membrane H+-ATPase. Plant Cell Physiol. 57, 2194-2201. doi: 10.1093/pcp/pcw136

Iuchi, S., Koyama, H., Iuchi, A., Kobayashi, Y., Kitabayashi, S., Kobayashi, Y., et al. (2007). Zinc finger protein STOP1 is critical for proton tolerance in Arabidopsis and corregulates a key gene in aluminum tolerance. Proc. Natl. Acad. Sci. U.S.A. 104, 9900-9905. doi: 10.1073/pnas.0700117104 
Kang, T. T., Kari, N. A., Maxwell, B. H., and Soquila, J. D. (2013). The effect of various $\mathrm{pH}$ levels on the root growth of Arabidopsis thaliana seedlings. Expedition 2. Available at: http://ojs.library.ubc.ca/index.php/ expedition/article/view/184145

Kobayashi, Y., Kobayashi, Y., Watanabe, T., Shaff, J. E., Ohta, H., Kochian, L. V., et al. (2013). Molecular and physiological analysis of $\mathrm{Al} 3+$ and $\mathrm{H}+$ rhizotoxicities at moderately acidic conditions. Plant Physiol. 163, 180-192. doi: 10.1104/pp.113.222893

Kochian, L. V., Hoekenga, O. A., and Piñeros, M. A. (2004). How do crop plants tolerate acid soils? Mechanisms of aluminum tolerance and phosphorus efficiency. Annu. Rev. Plant Biol. 55, 459-493. doi: 10.1146/annurev.arplant.55. 031903.141655

Kottb, M., Gigolashvili, T., Grobkinsky, D., and Piechulla, B. (2015). Trichoderma volatiles effecting Arabidopsis: from inhibition to protection against phytopathogenic fungi. Front. Microbiol. 6:995. doi: 10.3389/fmicb.2015.00995

Koyama, H., Toda, T., and Hara, T. (2001). Brief exposure to low-pH stress causes irreversible damage to the growing root in Arabidopsis thaliana: pectin-Ca interaction may play an important role in proton rhizotoxicity. J. Exp. Bot. 355, 361-368. doi: 10.1093/jexbot/52.355.361

Koyama, H., Toda, T., Yokota, S., Zuraida, D., and Hara, T. (1995). Effects of aluminium and $\mathrm{pH}$ on root growth and cell viability in Arabidopsis thaliana strain Landsberg in hydroponic culture. Plant Cell Physiol. 36, 201-205. doi: 10.1093/oxfordjournals.pcp.a078740

Lager, I., Andréasson, O., Dunbar, T. L., Andreasson, E., Escobar, M. A., and Rasmusson, A. G. (2010). Changes in external pH rapidly alter plant gene expression and modulate auxin and elicitor responses. Plant Cell Environ. 33, 1513-1528. doi: 10.1111/j.1365-3040.2010.02161.x

Lee, S., Yap, M., Behringer, G., Hung, R., and Bennett, J. W. (2016). Volatile organic compounds emitted by Trichoderma species mediate plant growth. Fungal Biol. Biotechnol. 3:7. doi: 10.1186/s40694-016-0025-7

López-Bucio, J., Pelagio-Flores, R., and Herrera-Estrella, A. (2015). Trichoderma as biostimulant: exploiting the multilevel properties of a plant beneficial fungus. Sci. Hort. 196, 109-123. doi: 10.1016/j.scienta.2015.08.043

Malamy, J. E., and Benfey, P. N. (1997). Organization and cell differentiation in lateral roots of Arabidopsis thaliana. Development 124, 33-44.

Marschner, H. (1991). Mechanisms of adaptation of plants to acid soils. Plant Soil. 134, 1-24. doi: 10.1007/BF00010712

Mastouri, F., Bjorkman, T., and Harman, G. E. (2010). Seed treatment with Trichoderma harzianum alleviates biotic, abiotic, and physiological stresses in germinating seeds and seedlings. Phytopathology 100, 1213-1221. doi: 10.1094/ PHYTO-03-10-0091

Mastouri, F., Bjorkman, T., and Harman, G. E. (2012). Trichoderma harzianum enhances antioxidant defense of tomato seedlings and resistance to water deficit. Mol. Plant Microbe Interact. 25, 1264-1271. doi: 10.1094/MPMI-09-110240

Murashige, T., and Skoog, F. (1962). A revised medium for rapid growth and bio assays with tobacco tissue cultures. Physiol. Plant. 15, 473-497. doi: 10.1111/j. 1399-3054.1962.tb08052.x

Nieto-Jacobo, M. F., Steyaert, J. M., Salazar-Badillo, F. B., Nguyen, D. V., Rostás, M., Braithwaite, M., et al. (2017). Environmental growth conditions of Trichoderma spp. affects indole acetic acid derivatives, volatile organic compounds, and plant growth promotion. Front. Plant Sci. 8:102. doi: 10.3389/ fpls.2017.00102

Ottenschläger, I., Wolff, P., Wolverton, C., Bhalerao, R. P., Sandberg, G., Ishikawa, H., et al. (2003). Gravity-regulated differential auxin transport from columella to lateral root cap cells. Proc. Natl. Acad. Sci. U.S.A. 100, 2987-2991. doi: 10.1073/pnas.0437936100

Prusky, D., Barad, S., Ment, D., and Bi, F. (2016). The pH modulation by fungal secreted molecules: a mechanism affecting pathogenicity by postharvest pathogens. Isr. J. Plant Sci. 63, 22-30. doi: 10.1080/07929978.2016.1151290

Rawat, L., Singh, Y., Shukla, N., and Kumar, J. (2013). Salinity tolerant Trichoderma harzianum reinforces $\mathrm{NaCl}$ tolerance and reduces population dynamics of Fusarium oxysporum f. sp. ciceri in chickpea (Cicer arietinum L.) under salt stress conditions. Arch. Phytopathology Plant Protect. 46, 1442-1467. doi: 10.1080/03235408.2013.769316

Salas-Marina, M. A., Silva-Flores, M. A., Uresti-Rivera, E. E., Castro-Longoria, E., Herrera-Estrella, A., and Casas-Flores, S. (2011). Colonization of Arabidopsis roots by Trichoderma atroviride promotes growth and enhances systemic disease resistance through jasmonic acid/ethylene and salicylic acid pathways. Eur. J. Plant Pathol. 131, 15-26. doi: 10.1007/s10658-011-9782-6

Samolski, I., Rincon, A. M., Pinzon, L. M., Viterbo, A., and Monte, E. (2012). The qid74 gene from Trichoderma harzianum has a role in root architecture and plant biofertilization. Microbiology 158, 129-138. doi: 10.1099/mic.0.053140-0

Sarkar, A. K., Luijten, M., Miyashima, S., Lenhard, M., Hashimoto, T., Nakajima, K., et al. (2007). Conserved factors regulate signalling in Arabidopsis thaliana shoot and root stem cell organizers. Nature 446, 811-814. doi: 10.1038/nature 05703

Sawaki, Y., Iuchi, S., Kobayashi, Y., Kobayashi, Y., Ikka, T., Sakurai, N., et al. (2009). STOP1 regulates multiple genes that protect Arabidopsis from proton and aluminum toxicities. Plant Physiol. 150, 281-294. doi: 10.1104/pp.108. 134700

Shavrukov, Y., and Hirai, Y. (2016). Good and bad protons: genetic aspects of acidity stress responses in plants. J. Exp. Bot. 67, 15-30. doi: 10.1093/jxb/erv437

Shoresh, M., Harman, G. E., and Mastouri, F. (2010). Induced systemic resistance and plant responses to fungal biocontrol agents. Annu. Rev. Phytopathol. 48, 1-23. doi: 10.1146/annurev-phyto-073009-114450

Singh, A., Shahid, M., Srivastava, M., Pandey, S., Sharma, A., and Kumar, V. (2014). Optimal physical parameters for growth of Trichoderma species at varying $\mathrm{pH}$, temperature and agitation. Virol. Mycol. 3:127. doi: 10.4172/2161-0517. 1000127

Sofo, A., Tataranni, G., Xiloyannis, C., Dichio, B., and Scopa, A. (2012). Direct effects of Trichoderma harzianum strain T-22 on micropropagated shoots of GiSeLa6 ${ }^{\circledR}$ (Prunus cerasus $\times$ Prunus canescens) rootstock. Environ. Exp. Bot. 76, 33-38. doi: 10.1016/j.envexpbot.2011.10.006

Stat Soft Inc (2011). STATISTICA, version 10. Available at: www.statsoft.com

Trushina, N., Levin, M., Mukherjee, P. K., and Horwitz, B. A. (2013). PacC and $\mathrm{pH}$-dependent transcriptome of the mycotrophic fungus Trichoderma virens. BMC Genomics 14:138. doi: 10.1186/1471-2164-14-138

van den Berg, C., Willemsen, V., Hendriks, G., Weisbeek, P., and Scheres, B. (1997). Short-range control of cell differentiation in the Arabidopsis root meristem. Nature 390, 287-289. doi: 10.1038/36856

von Uexküll, H. R., and Mutert, E. (1995). Global extent, development and economic impact of acid soils. Plant Soil. 171, 1-15. doi: 10.1007/BF0000 9558

Yokota, S., and Ojima, K. (1995). Physiological responses of root tips of alfalfa to low $\mathrm{pH}$ and aluminium stress in water culture. Plant Soil. 171, 163-165. doi: 10.1007/978-94-011-0221-6_46

Yuan, Z. C., Liu, P., Saenkham, P., Kerr, K., and Nester, E. W. (2008). Transcriptome profiling and functional analysis of Agrobacterium tumefaciens reveals a general conserved response to acidic conditions ( $\mathrm{pH} 5.5)$ and a complex acid-mediated signaling involved in Agrobacterium-plant interactions. J. Bacteriol. 190, 494-507. doi: 10.1128/JB.01387-07

Zeng, Q. L., Huang, X. H., and Zhou, Q. (2005). Effect of acid rain on seed germination of rice, wheat and rape. Environ. Sci. 26, 194-197.

Conflict of Interest Statement: The authors declare that the research was conducted in the absence of any commercial or financial relationships that could be construed as a potential conflict of interest.

Copyright (C) 2017 Pelagio-Flores, Esparza-Reynoso, Garnica-Vergara, López-Bucio and Herrera-Estrella. This is an open-access article distributed under the terms of the Creative Commons Attribution License (CC BY). The use, distribution or reproduction in other forums is permitted, provided the original author (s) or licensor are credited and that the original publication in this journal is cited, in accordance with accepted academic practice. No use, distribution or reproduction is permitted which does not comply with these terms. 